\title{
Article \\ Ti-6Al-4V Octet-Truss Lattice Structures under Bending Load Conditions: Numerical and Experimental Results
}

\author{
Francesco Di Caprio ${ }^{1, *(\mathbb{D})}$, Stefania Franchitti ${ }^{1}$, Rosario Borrelli ${ }^{1}\left(\mathbb{D}\right.$, Costanzo Bellini $^{2}$, Vittorio Di Cocco ${ }^{2}$ \\ and Luca Sorrentino ${ }^{2}$ iD \\ 1 CIRA-Italian Aerospace Research Centre, Via Maiorise, 81043 Capua, CE, Italy; s.franchitti@cira.it (S.F.); \\ r.borrelli@cira.it (R.B.) \\ 2 Department of Civil and Mechanical Engineering, University of Cassino and Southern Lazio, \\ 03043 Cassino, FR, Italy; c.bellini@unicas.it (C.B.); vittorio.dicocco@unicas.it (V.D.C.); \\ luca.sorrentino@unicas.it (L.S.) \\ * Correspondence: f.dicaprio@cira.it; Tel.: +39-0823623538
}

Citation: Di Caprio, F.; Franchitti, S.; Borrelli, R.; Bellini, C.; Di Cocco, V.; Sorrentino, L. Ti-6Al-4V Octet-Truss Lattice Structures under Bending Load Conditions: Numerical and Experimental Results. Metals 2022, 12, 410. https://doi.org/10.3390/ met12030410

Academic Editor: Yousub Lee

Received: 6 January 2022

Accepted: 25 February 2022

Published: 26 February 2022

Publisher's Note: MDPI stays neutral with regard to jurisdictional claims in published maps and institutional affiliations.

Copyright: (C) 2022 by the authors. Licensee MDPI, Basel, Switzerland. This article is an open access article distributed under the terms and conditions of the Creative Commons Attribution (CC BY) license (https:/ / creativecommons.org/licenses/by/ $4.0 /)$.

\begin{abstract}
Metal lattice structures produced by means of additive techniques are attracting increasing attention thanks to the high structural efficiency they can offer. In order to achieve the maximum structural performance, numerical design techniques are used almost exclusively, thus based on CAE-FEM codes. Nevertheless, the current manufacturing facilities do not yet guarantee defect-free components, and, therefore, such imperfections need to be introduced in the numerical models too. The present work aims to describe a FE modelling technique for lattice structures based on the use of beam and shell elements, and therefore with a very reduced computational cost. The main structural parameters, such as weight and stiffness and strength, are used to drive the model calibration. Simple mathematical relationships, based on Experimental-CAD-FEM comparisons, are provided to estimate the error related to the numerical model in a simple and fast way. The validation was performed by three-point bending test on flat specimen with regular octet-truss microstructure both with and without external skin. The test articles were produced in Ti6Al4V and by means of the electron beam melting (EBM) technology. The results obtained are in excellent agreement with the experimental ones, indeed the maximum error is about 3\%. All this indicates these methodologies as possible tools for evaluating the performance of such kinds of high-tech structures.
\end{abstract}

Keywords: lattice structure; octet truss; titanium alloy; lightweight structure; EBM; FEM; experimental testing; three-point bending

\section{Introduction}

Nowadays, the aeronautical and automotive sectors require materials with high mechanical characteristics coupled to low weight, since fuel consumption must be reduced, and consequently pollutant gas emission, without affecting the safety levels [1]. Lattice structures are suitable for these aims [2,3]. In fact, especially for metallic materials, the specific mechanical properties (in particular, strength-to-weight and stiffness-to-weight ratios) that are achieved by cellular solids cannot be obtained by the base material in the dense form [4]. Lattice structures are constituted by several unit cells, that are systematically organized in the space in compliance with a topological sequence [5]. Several processes can be adopted to produce lattice structures, such as casting, machining, filament winding and hot pressing. However, today additive manufacturing processes have reached a high level of reliability; consequently, they can be considered for the manufacturing of lattice structures [6]. In the past, lattice structures with different unit cell dimensions were produced and tested by Epasto et al. [7], who found that the worst mechanical behaviour corresponded to the structures with the largest cells. Lattice structures with functionally graded porosity were studied by Mahbod and Asgari [8] to achieve a better response to crush loads. The lattice structures can be used as core material in sandwich structures, 
because they present remarkable advantages from the points of view of both the mechanical properties and the manufacturing process compared to honeycomb ones [9]. Moreover, the sandwich skin can be printed together with the core or added in a subsequent manufacturing step: in such a manner, it is possible to combine different materials to obtain hybrid structures [10].

Nowadays a possible strategy to expand the boundaries of material-property space is to use hybrid material design capabilities. In other words, new materials can be determined by combining two or more monolithic materials in a well-defined configuration and connectivity. In particular, Ashby [11] has underlined that the capabilities of the octet lattice structures could expand the boundaries of material-property space, increasing the specific strength and stiffness and in particular the flexural characteristics.

To obtain the maximum performance it is very important to define new design strategies which can support engineers during the design process. Ashby [11,12] describes the rationale for creating architecture materials and criteria for deciding which combinations and configurations show the most promise. Fleck et al. [13] also describe the ability of micro-architectured lattice materials to provide a wide range of strength, stiffness and fracture toughness, emphasizing the role of nodal connectivity and structural hierarchy.

Lattice structures can be divided into several main categories and sub-categories; among these, we have the bending-dominated and stretch-dominated behavior [11]. The modulus and the initial collapse strength of a stretch-dominated lattice are much greater than those of a bending-dominated one with the same relative density. This makes stretchdominated cellular solids the best choice for lightweight structural applications. Among those, particular attention has been given to octahedral cells which, classified as stretchdominated structures, can form a rigid framework reaching a very high structural efficiency. Deshpande et al. [14] have recently analyzed the criteria for the construction of stretchdominated cellular materials. A sufficient condition to have a stretch-dominated periodic structure, is that the unit cell of the structure satisfies Maxwell's criterion for static determinacy. Deshpande et al. [15] investigated the effective mechanical properties of octet-truss lattice structures, from both an experimental, numerical and theoretical point of view. They offer a deep analysis not only of the elastic properties, but also of the collapse criteria with and without buckling conditions. Furthermore, they provide a comparison between octet-truss lattice materials and metallic foam in terms of strength and stiffness. The stiffness and strength of the octet-truss lattice material exceed the corresponding values for metallic foams by a factor between 3 and 10, and are about half the theoretical maximum values for isotropic voided materials. Thus, its high strength-to-weight ratio, relative ease of manufacture and potential for multi-functional applications makes the octet-truss lattice material an attractive alternative to metallic foams.

It is well known that parts manufactured with additive techniques may include several defects within them [16,17]. These defects, such as voids, can affect the performance of structural components and, therefore, such imperfections need to be introduced in the numerical models too. Regardless of the type of technology used for the production of metal AM parts, it is possible to find different types of defects in final products. Defects can essentially be grouped into two categories: internal defects (pores, micro-voids, lack of fusion (LOF), residual stresses) and external defects (surface roughness). All of them can affect the global mechanical properties at different levels and sometimes in a very significant way [18-21]. Furthermore, there are parameters, at microscale level, that influence the mechanical properties at the macro level. For example, the plasticity is related to the activation of microscopic deformation mechanisms such as dislocation slip or mechanical twinning. The latter is influenced by the grain size, therefore controlling these ones mean being able to modify the characteristics of ductility and fracture toughness [22].

Such defects play an important role when the dimensions of the components are small enough, as in the case of the lattice structures in which the diameter of the single truss is in the order of millimeters or less. Hernandez-Nava et al. [23] proposed an in-depth study of the defects found in lattice structures produced by EBM-type additive techniques, 
while Ferrigno et al. [24] provided a methodology for embedding, in lattice structures with regular octet cells, generic defects with a random distribution. Such approach is useful to evaluate the dependency of the mechanical performance on discrete defects generated during the EBM processes.

Lattice structures, thanks to the progress of additive manufacturing, have more possibilities of use in practical applications now their cost can be competitive, but at the same time, it is very important to develop design methods that can allow capturing the full potential of designed lattice materials.

Several optimization procedures were proposed to design efficient lattice structures but much more has to be done to provide a method applicable in any industrial field. Moreover, the need to apply such structural architectures to large and complex structures demands very efficient design methods. Most design approaches aim to design the internal volume of a structure by filling it with periodic and repetitive regular elementary cells [25-27]. The advantages of such approaches consist in their fast modeling and fabrication, as well as in the possibility of predicting their mechanical properties. On the other hand, non-uniform lattice structures, i.e., with variable elementary cells, can provide a more tailored distribution of elements aimed at achieving improved mechanical performance. Generally, such problems are addressed by means of homogenization-based approaches [28-31] which are based on homogenization theory [32,33]. Chen et al. [34] presented a parametrization modeling approach based on pre-generated meshes that is applicable to large structures. The two kinds of unit cell (primitive and derivative) allow one to fill the internal volume and to adjust their nodes to concentrate materials in more stressed regions. Rosen [35] developed a new design for additive manufacturing method which allows the design of meso-structures within a part for achieving improved stiffness, strength, or some other functional requirement, as compared to monolithic materials. Zhang et al. [36] discussed the necessary considerations and potential constraints when designing for AM, introduce the process planning for AM and, based on that, proposed a two-level evaluation framework for the design in AM as well as identify some common indicators for assessment. Di Caprio et al. [37] developed a numerical method for designing and optimizing lattice structures based on full-parametric numerical models to be used in conjunction with multi-objective genetic algorithms.

The present work aims to describe a methodology to analyze the lattice structures with regular octet-truss cells, based on simplified numerical models with a discrete representation of the cells and with a reduced computational cost. The numerical models are generated automatically by means of an APDL macro to be used in the ANSYS environment. This allows one to generate, in negligible time, different shapes and different types of elementary cells and to perform a rapid assessment of the structural performances both with linear and non-linear analysis methods (thus also incorporating the yielding effects and any localized instabilities). By means of experimental tests it was possible to calibrate and therefore validate such models. In addition, with the using of detailed CAD models, simple empirical relationships have been defined for indirectly obtaining the effective diameters of the trusses making up the cells and evaluating the mass error of the simplified FE models.

The reduction of the mechanical properties due to the presence of defects has been treated with a simplified method which works directly on the global geometric characteristics. After a preliminary evaluation performed with respect to the experimental mass measures, a further modification of the geometric characteristics is performed. The latter is equivalent to having a kind of defect state uniformly distributed in the structure. Basically, the method can be classified as an indirect method since the diameter is evaluated by the total mass measurement. Indeed, with only one parameter, i.e., the total mass, it is possible to estimate the diameter that provides a small difference with respect to the experimental data Therefore, the diameter reduction is a simple method to take into account all geometrical imperfections and internal defects/porosities, from a mechanical point of view. Moreover, 
the proposed method allows having a reduced computational cost, and this is one of the main objectives of the work.

\section{Materials and Methods}

The study of lattice structures, from a numeric point of view, requires the development of specific methodologies in order to reduce the design effort. Modelling such structures in interactive mode is very tedious and tricky. In order to analyze a great range of structures with different types of unit cells, a dedicated script was developed and implemented in ANSYS code and in the present work it was used for studying the mechanical response of octet-truss cells. Hereafter a brief description of the adopted numerical model is provided and some details about the specimens manufactured by the additive process.

\subsection{Numerical Model Description}

The full-parametric macro was written entirely in Ansys Parametric Design Language (APDL) and allows one to manage, in a simple and effective way, not only the pre-processing phase, but also the solution and post-processing ones. In particular, the most valuable part of the macro is represented by the automated generation of the FE model of the lattice structures under investigation, with the option for implementing the outer skins (both in composite and titanium). Starting from the definition of the cells' parameters to be modelled, the entire lattice structure will be generated in a fully automated way.

In order to increase the computational efficiency, the whole FE model is built up with beam and shell elements (both linear, therefore with two and four nodes, respectively, and six DOFs per node). The first ones are used to discretize all trusses of the unit cells and the second ones are used to model the optional skins. Furthermore, a specific interfacing procedure totally remove the need to introduce multi-point constraint (MPC) elements between the beam and shell elements to ensure the structural continuity. Therefore, the lattice core and the skins are connected by sharing the interfacing nodes, regardless of the topology of the structure to be analyzed. All this increases the accuracy of the results, minimizes any convergence difficulties and, on the other hand, reduces the computational cost.

Figure 1 shows some details of the lattice part considering a generic FE model. Each unit cell (e.g., octo-truss) can be considered as the combination of two regular tetrahedra and a central body consisting of other two tetrahedra that share the same square base.

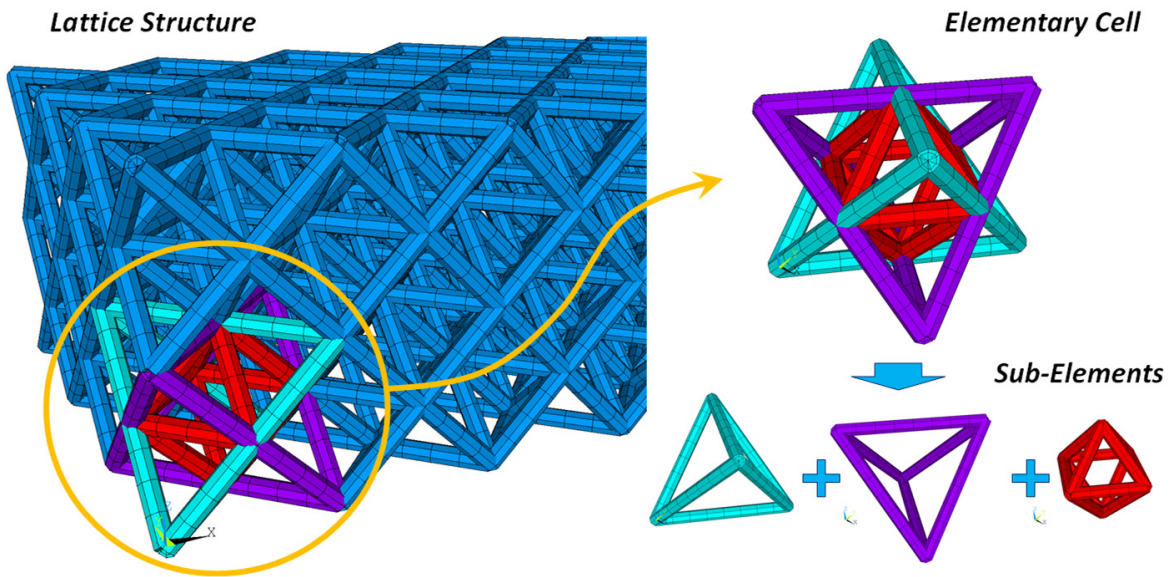

Figure 1. Finite element model of the lattice structure with octet-truss unit cell.

The developed macro was used to create both the structures without skins and those ones with outer skins. Figure 2 shows the complete FE model with outer skins, and it is possible to appreciate the perfect correspondence of the cells' nodes with skin's ones. 


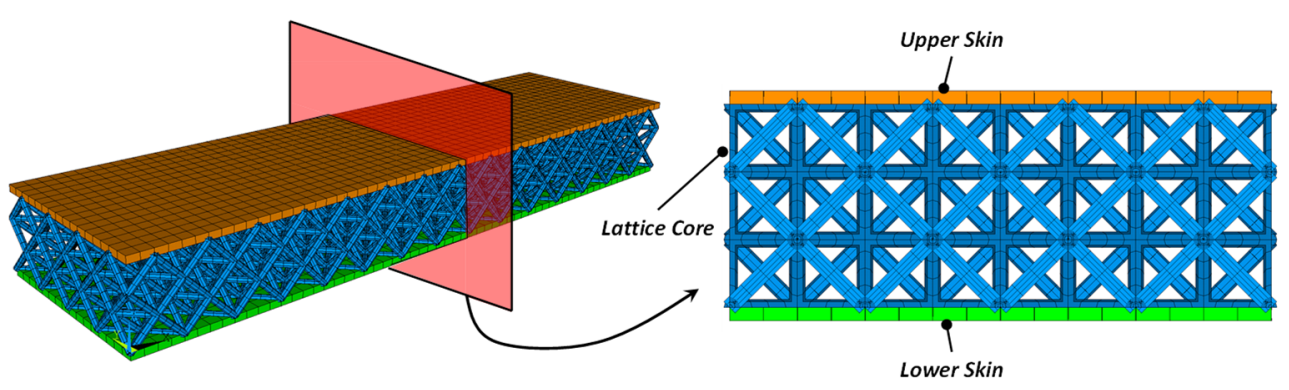

Figure 2. Investigated specimen with outer skins with the 3D-visualization of shell and beam sections.

Each truss is discretized with four elements (beam), while the average size of the skin element is about $2 \mathrm{~mm}$. In such a way it is possible to simulate the deformation states with good accuracy and maintain a reduced computational cost. A mesh convergence analysis has been performed, but it is not reported herein for sake of brevity.

The numerical model without the external skins has 37,200 linear beam elements (used to discretize the elementary cell trusses) and 11,520 linear 3D brick solid elements (used to discretize the supports and the loading block, as reported in Figure 3). The same parameters are applicable to the model with outer skins, but in this case, there are also an additional 7200 linear shell elements which are used to discretize the skins. The average computational cost is about $650 \mathrm{~s}$ for the model without the skins and about $900 \mathrm{~s}$ for the model with outer skins. The machine used for the numerical simulation is a HP Z840 workstation, equipped with an Intel Xeon E5-2620 v3 CPU @ 2.40 GHz and 128 GB RAM.

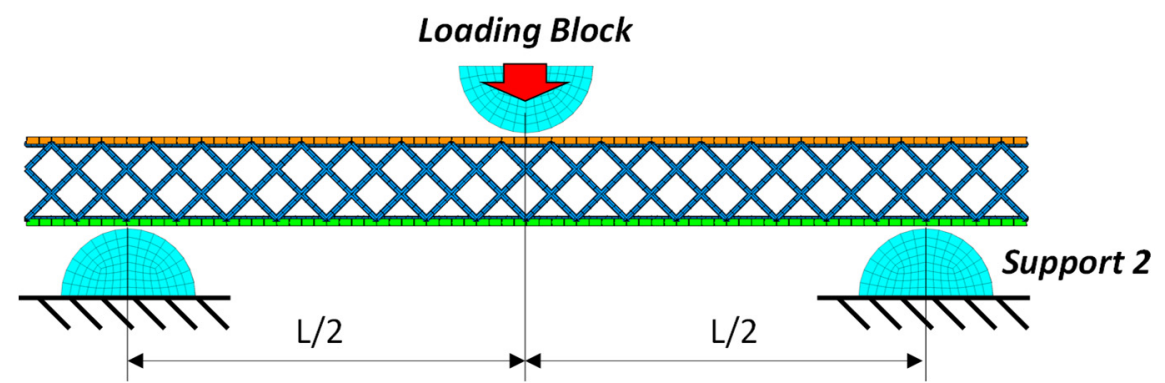

Figure 3. Applied boundary conditions by modelling the metallic support and the loading block.

Finally, in order to apply the experimental boundary conditions as faithfully as possible, the rollers of the test fixture were also modelled and specific contact conditions were applied between the fixture and the specimens, in particular a frictionless interaction has been defined. The rollers have been modelled with solid 8-node hexahedral elements and stainless-steel material properties were applied (Young modulus $=210 \mathrm{GPa} ; \mathrm{v}=0.33$ ). Because no critical deformation was expected on the rollers and loading block, no plastic and failure behaviour were implemented. Modelling the fixture with continuous material reduces the possibility of overestimating the stiffness coefficients of the adopted penalty method.

Figure 3 schematically shows the applied boundary conditions. The bottom faces of lower supports are constrained in all degrees of freedom, while the upper roller (loading block) is free to move perpendicularly to the upper skin in order to generate a bending deformation state. The spacing span L is equal to $200 \mathrm{~mm}$. All analyses are performed in a non-linear regime with material, contact and geometric non-linearity.

The material properties adopted for the present study are reported in Table 1. In particular, in numerical analyses, the material has been considered as multi-linear elastoplastic material with isotropic hardening. They refer to as-built component (no post processing treatments) and were evaluated in previous works [38] 
Table 1. Material mechanical properties.

\begin{tabular}{cccccc}
\hline $\begin{array}{c}\text { Density } \\
\left(\mathbf{g} / \mathbf{c m}^{\mathbf{3}}\right)\end{array}$ & $\begin{array}{c}\text { Young Modulus } \\
\mathbf{( M P a )}\end{array}$ & Poisson Ratio & $\begin{array}{c}\text { Yield Stress } \\
\mathbf{( M P a )}\end{array}$ & Tangential Modulus (MPa) & $\begin{array}{c}\text { Ultimate Strain } \\
\mathbf{( \% )}\end{array}$ \\
\hline 4.4 & 104,800 & 0.33 & 857 & $\begin{array}{c}\left.2900 \text { (from } \varepsilon_{\text {yield }} \text { up to } \varepsilon=0.04\right) \\
0 \text { (from } \varepsilon=0.04 \text { up to failure) }\end{array}$ \\
\hline
\end{tabular}

\subsection{Specimen Manufacturing}

In order to support the numerical analysis and to validate the FEM model, several lattice specimens were manufactured by using the electron beam melting (EBM) technology. In this section, details of the manufacturing activity, consisting in an overview of the material used in this study, as well as the process parameters chosen and the test specimens manufactured, will be provided. The EBM system used in this study was the Arcam A2X. This system $[39,40]$ allows solid parts to be directly manufactured from metal or alloy powders.

\subsubsection{Material Details}

Specimens used in this study were manufactured by using Ti6Al4V atomized powder with spherical morphology. The spherical shape contributes to improved flowability, and thus, ensures high build rates and part accuracy [41]. The powder flow rate measured according to ASTM B213 was found $25 \mathrm{~s} / 50 \mathrm{~g}$. The apparent density according to ASTM B212 was $2.57 \mathrm{~g} / \mathrm{cm}^{3}$. As far as the particle size distribution is concerned, the percentage by mass of particle size in the range $45-106 \mu \mathrm{m}$ was found equal to $93.6 \%$ (Figure 4 ). The nominal chemical composition of the powder is summarized in Table 2.

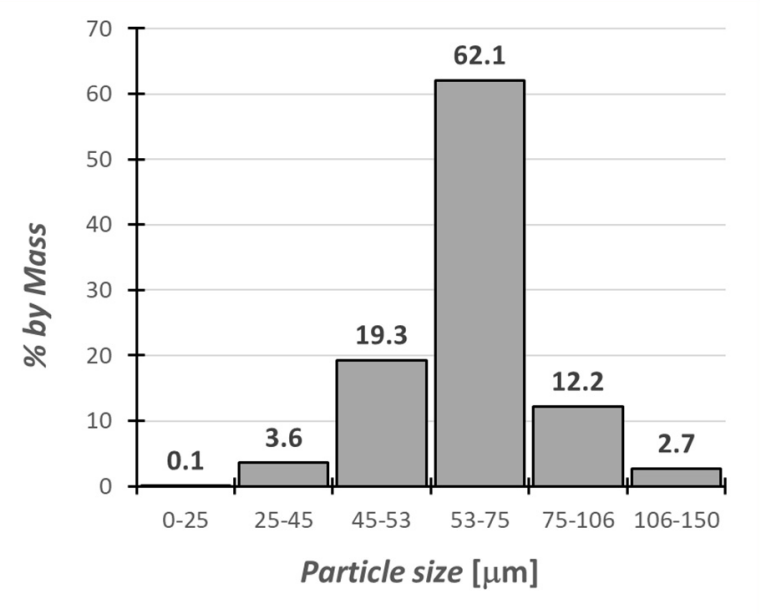

Figure 4. Ti6Al4V powder particle size distribution.

Table 2. Nominal chemical composition of the Ti6Al4V pre-alloyed powder.

\begin{tabular}{ccc}
\hline Chemical Element & \% & Required \% ASTM F2924 \\
\hline $\mathrm{Al}$ & 6.40 & $5.50-6.75$ \\
$\mathrm{~V}$ & 4.12 & $3.50-4.50$ \\
$\mathrm{Fe}$ & 0.18 & $<0.30$ \\
$\mathrm{O}$ & 0.14 & $<0.20$ \\
$\mathrm{~N}$ & 0.01 & $<0.05$ \\
$\mathrm{H}$ & 0.003 & $<0.015$ \\
$\mathrm{C}$ & 0.01 & $<0.08$ \\
$\mathrm{Ti}$ & Balance & Balance \\
\hline
\end{tabular}




\subsubsection{Specimens Description}

Two different configurations of specimens were manufactured:

- $\quad$ Lattice structure specimens without outer skins (Type01)

- Lattice structure specimens with outer skins (Type02)

The elementary cell of the lattice structure is an octet-truss with a characteristic length (length of the elementary cell) equal to $6 \mathrm{~mm}$ and specific density (ratio between the volume occupied by the trusses and the total volume of the elementary cell) equal to about $30 \%$. This elementary cell configuration leads to a nominal strut diameter of $1.0 \mathrm{~mm}$.

The dimensions of lattice structure are $270 \times 30 \times 9 \mathrm{~mm}$, hence 45 unit cells were repeated along the length direction, six cells were repeated along the width direction and 1.5 cells were repeated through the thickness.

The outer skins, of the second specimen configuration, are $0.6 \mathrm{~mm}$ thick and they were EBMed together with the lattice core on both faces of the specimen. The geometry and dimensions (millimeters) of the samples are shown in Figure 5A,B, respectively.

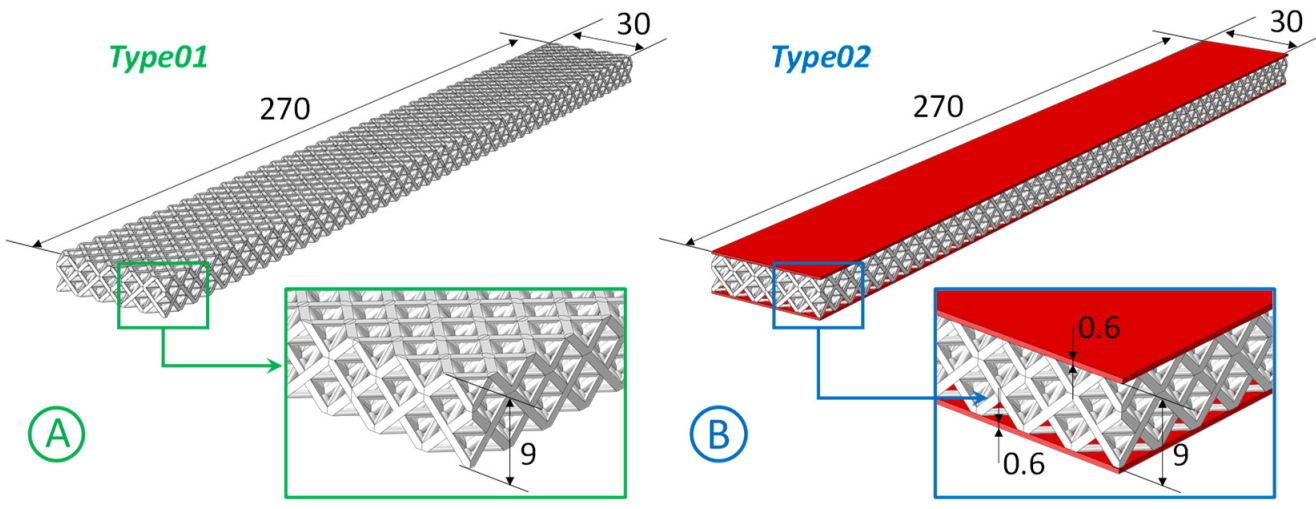

Figure 5. (A) Geometry of the lattice specimen without outer skin (type01); (B) Geometry of the lattice specimen with outer skins (type02).

\subsubsection{Manufacturing Process Description}

The process themes were set through the "EBM control 3.2" software installed on the ARCAM A2X EBM system. The "automatic" operating mode of the EBM system was selected and the following three standard process themes for Ti6Al4V alloy and layer thicknesses of $50 \mu \mathrm{m}$ were used:

(1) "Ti6Al4V-PreHeat-50 $\mu \mathrm{m}$ ": process theme that control the phase of preheating of the whole powder bed.

(2) "Ti6Al4V-Melt-50 $\mu \mathrm{m}$ ": process theme used for the realization of the solid part of the specimen (outer skins).

(3) "Ti6Al4V-Net-50 $\mu \mathrm{m}$ ": process theme used for the realization of the lattice part of the specimen (lattice core).

These build themes vary the electron beam parameters in a controlled sequence throughout the build according to algorithms developed by the manufacturer in an effort to achieve fully dense as-built parts with consistent microstructures and properties. Since the algorithm is copyrighted, the beam current and beam speed time-dependent diagrams are hidden from users. A line offset of $0.1 \mathrm{~mm}$ was set.

The orientation and the location of the samples in the build chamber were set by using the Materialise Magics software (Materialise, Leuven, Belgium).

In this work, a single grow orientation was considered. In particular, the samples were manufactured in the $\mathrm{z}$-direction growth orientations.

All the specimens were scaled according to the ARCAM recommended scale factors in order to take into account for the thermal shrinkage occurring after the melting. 
All the specimens were manufactured in a single job shown in Materialise Magics environment in Figure 6A.
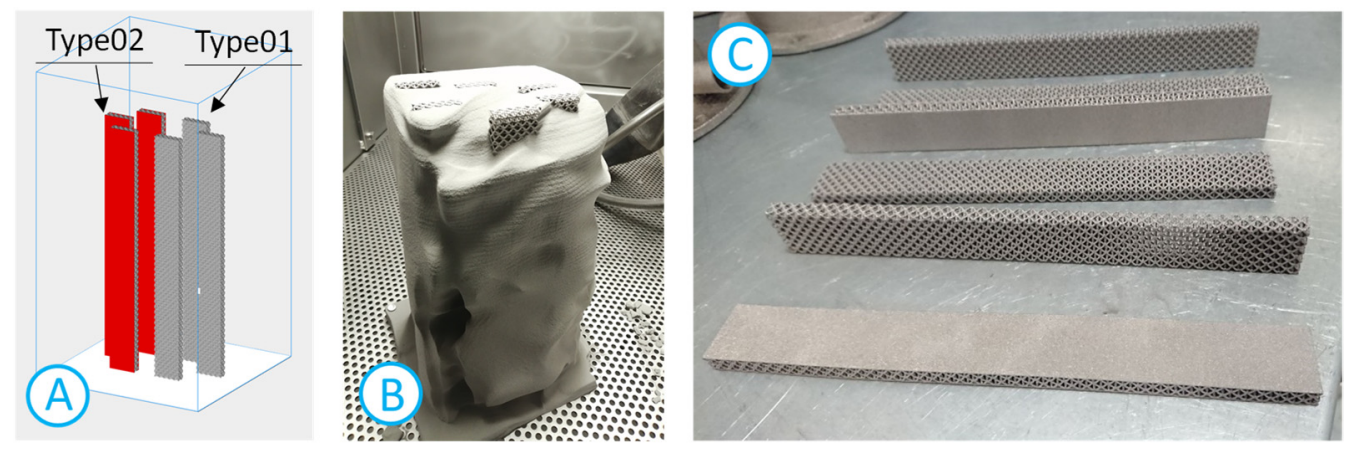

Figure 6. (A) Job layout; (B) specimen at the end of the manufacturing process; (C) post-processed specimens.

At the end of the manufacturing process the build was moved with a trolley directly to the powder recovery system (PRS, Figure 6B) to remove and recover the sintered powder from around the specimens. PRS uses metal powder of the same alloy to blast the loosely sintered powder grains from the surface and remove the preheat cake.

Once the build was cleaned of powder, the specimens were labeled and ready to be tested (Figure 6C).

EBM technology does not require any post-manufacturing heat treatment. The only treatment recommended by ARCAM is HIP, which aims to reduce critical porosities for components subject to fatigue loads. Because of the components analysed in this work are subject to static loads only, no HIP treatment any other heat treatment was performed.

\section{Considerations on the Trusses' Diameter}

After the manufacturing process of the specimens, some measurements were carried out in order to determine the real geometric parameters. Considering the specimens' complexity level (composed of thousands of trusses) it is not possible to accurately determine the real size of each part and for this reason only global mass and diameter of few trusses were measured.

The global mass of the specimen can be useful to quickly estimate the real diameter of the trusses, hypothesizing a uniform mass distribution.

The measured average mass (based on three specimens) is equal to $63.81 \mathrm{~g}$ while the nominal mass, determined by the CAD, is equal to $90.07 \mathrm{~g}$. Such reduction, of about $29 \%$, can be related to the reduction in diameter of all trusses. In order to evaluate the diameter that provide such measured mass, several CAD models were defined, because of an analytical approach is not easy to manage due to the geometrical complexity described more in detail in the following. Then a fitting curve was determine interpolating the mass values evaluated by CAD. In particular, six models were developed with the trusses' diameter ranging from 0.5 up to $1.0 \mathrm{~mm}$ (nominal value).

Figure 7 shows two specimens made with two different diameters that are the biggest and smallest ones (1.0 and $0.5 \mathrm{~mm})$. The fitting curve, that provide the relationship between the diameter of the trusses and the total mass, is not linear and a third order polynomial results the best approximation (1):

$$
M_{C A D}=-28.69044 D^{3}+118.77706 D^{2}-0.01296 D+0.00267
$$




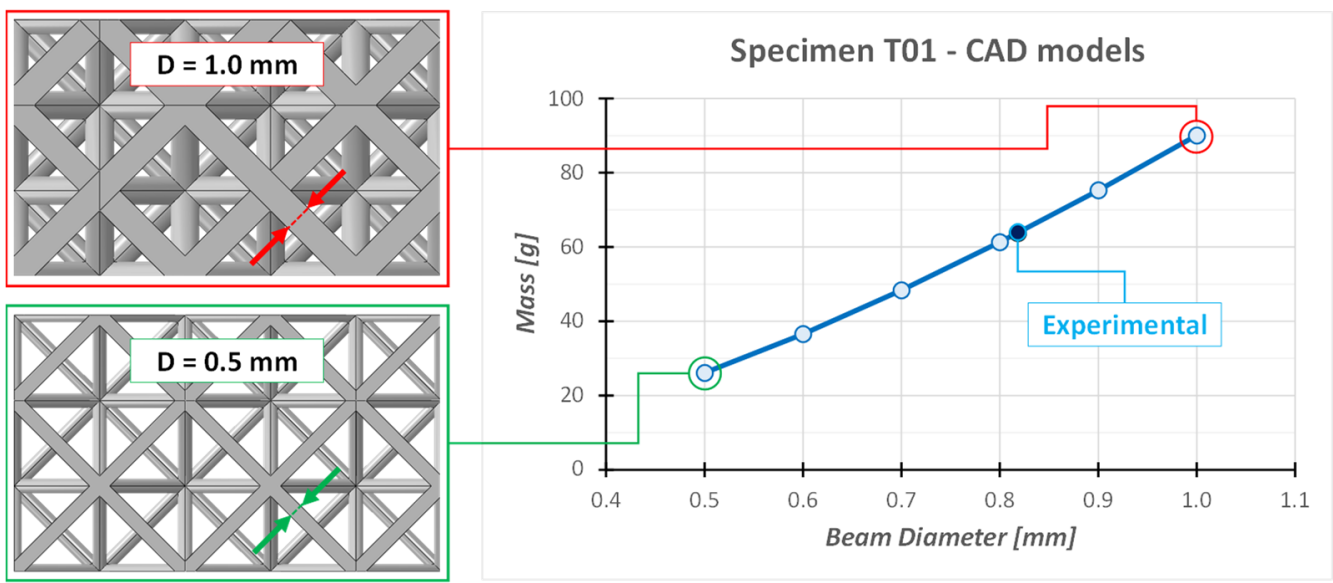

Figure 7. Truss's diameter vs. specimen mass and section view of the upper and lower limits.

Equation (1) provides the theoretic value of the trusses' diameter $\left(\mathrm{D}_{\mathrm{T}}\right)$ which allows one to match the measured experimental mass $(63.81 \mathrm{~g})$, that is $0.818328 \mathrm{~mm}$. Obviously, this value does not take into account any amount of powder that was not completely melted (and therefore not completely removed) which, even if it does not contribute to the structural strength, does contribute to the definition of the final weight. Therefore, considering a mass reduction of about $29 \%$, the reduction in diameter corresponds to $18 \%$.

It is possible to extend the considerations on the mass-diameter relationship to the developed FE model. As previously reported, the FE model is made up of 1D beam elements, and thus a specific section (full circle or semi-circle) is associated to them. In particular, the FE model, regardless of the defined diameter, will always provide a higher mass value, due to the impossibility of eliminating the overlapping regions at the connection points of the trusses. Figure 8 shows a simplified 2D schematization of the overlapping region among several trusses (assumed discretized with 1D beam elements with circular section). Even in such simplified condition the global mass can be considerably overestimated since there are several regions with up to four overlapping (the number reported indicates how many times an area is considered in the mass estimation). Obviously, the bigger the diameter is, the grater the error will be.

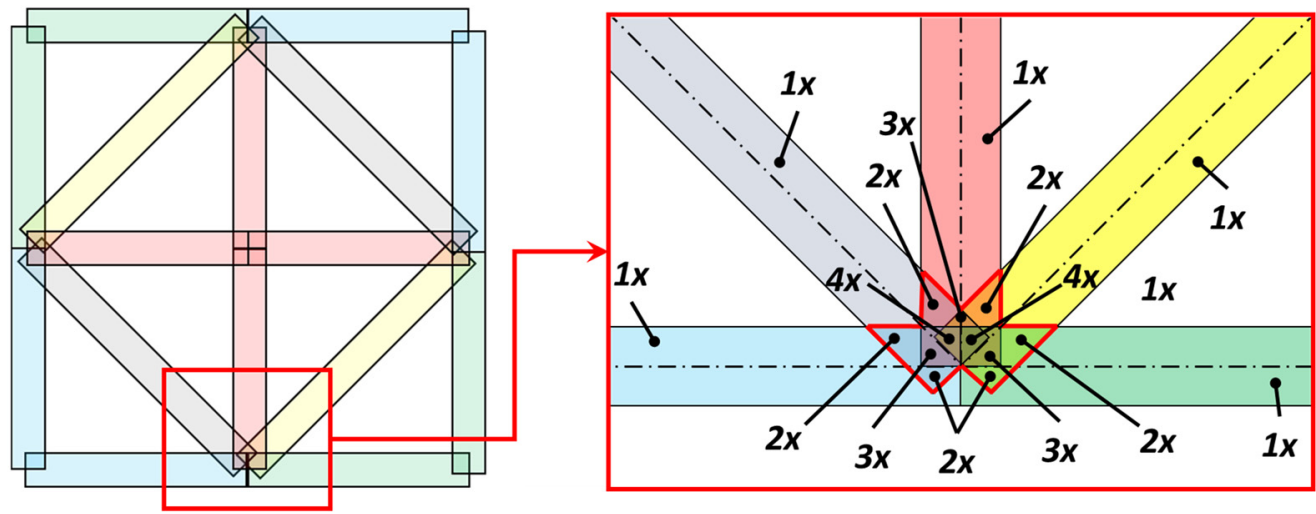

Figure 8. Schematization of overlapping regions.

Furthermore, in the 3D cell at the same generic connection point, highlighted in the previous figure, up to 12 trusses converge, and sometime, in a given point, beams with different section can converge (the outer trusses have a semi-circular section).

Figure 9 shows a single 3D unit cell with the overlapping regions. It is possible to see that the shape is much more complex as it derives from the intersection of cylinders oriented at $45^{\circ}$ with respect to each other. The petal-like shape is different for the central and external connection points. 

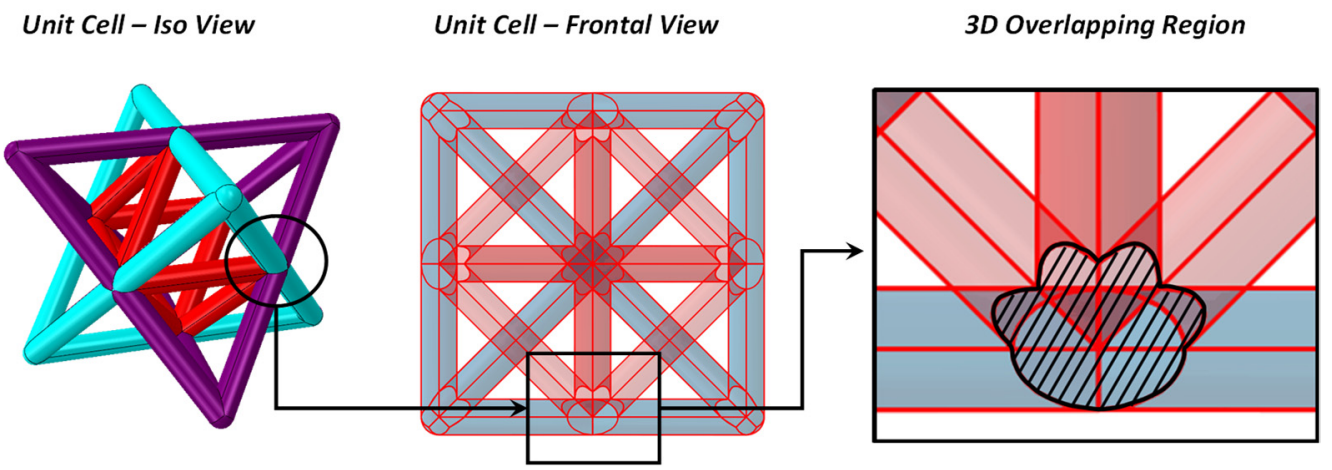

Figure 9. Overlapping region in 3D real unit cell.

The developed CAD models provide the mass reference values that can be used to evaluate the overestimation in mass related to the FE models made up of 1D beam elements. The volume, and thus the mass, of the 1D-FE model can be easily computed by the truss diameter, the number of cells and the number of truss for each of them, as well as, obviously, from the FE model. By comparing these ones with the right mass determined by the CAD model, it is possible to indirectly determine the extra mass associated to the 1D-FE model.

Table 3 reports the mass evaluated by using the FE and CAD models and difference between them that correspond to the overestimated ones. The error, related to the nominal diameter, is quite large and it is about $31 \%$. Reducing the trusses' diameter, the error decreases, but it is still not neglectable.

Table 3. Total Mass for 1D-FE and CAD models.

\begin{tabular}{cccccc}
\hline $\begin{array}{c}\text { Configuration } \\
\text { IDs }\end{array}$ & $\begin{array}{c}\text { Truss Diameter } \\
(\mathbf{m m})\end{array}$ & $\begin{array}{c}\text { FE Model } \\
\mathbf{( 1 D )}(\mathbf{g})\end{array}$ & $\begin{array}{c}\text { CAD } \\
\mathbf{( g )}\end{array}$ & $\begin{array}{c}\text { Extra Mass } \\
\mathbf{( g )}\end{array}$ & $\begin{array}{c}\text { Difference } \\
\mathbf{( \% )}\end{array}$ \\
\hline Config 01 & 1.0 & 118.758 & 90.076 & 28.682 & 31.842 \\
Config 02 & 0.9 & 96.194 & 75.285 & 20.909 & 27.773 \\
Config 03 & 0.8 & 76.005 & 61.320 & 14.685 & 23.948 \\
Config 04 & 0.7 & 58.192 & 48.354 & 9.838 & 20.346 \\
Config 05 & 0.6 & 42.753 & 36.558 & 6.195 & 16.947 \\
Config 06 & 0.5 & 29.690 & 26.104 & 3.585 & 13.735 \\
\hline
\end{tabular}

Similar data are reported in Figure 10A,B from a graphical point of view. In particular the figures report the extra mass (overestimation) and the absolute mass value as a function of the diameter.
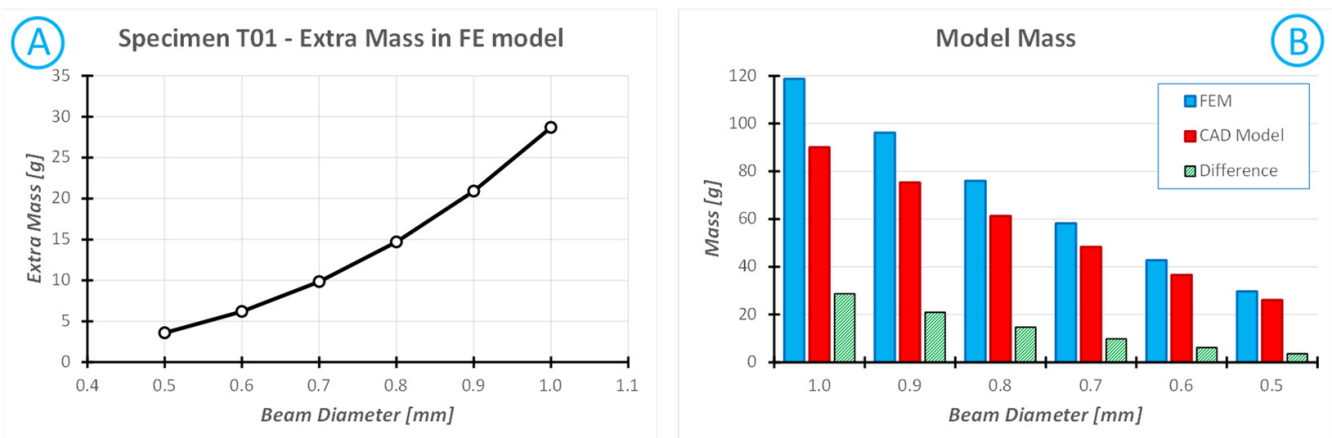

Figure 10. (A) Overestimated mass in FE models; (B) Mass comparison between FE and CAD. 
The extra mass has a non-linear dependence on the beams' diameter. Also in this case it is possible to obtain the regression curve by interpolating the right values evaluated in the control points (markers in Figure 10A):

$$
M_{F E}^{\text {extra }}=-28.69 D^{3}-0.0225 D^{2}+0.0154 D-0.0032
$$

The extra mass of the FE model with the reduced diameter, based on the real mass, $(\mathrm{d}=0.8183 \mathrm{~mm}$ ) is equal to $15.716 \mathrm{~g}$ and thus the estimated mass of the FE model made of $1 \mathrm{D}$ beam elements is equal to $79.552 \mathrm{~g}$. Such a value can be easily obtained in FE software and it corresponds to the relationship: $M_{F E}=M_{C A D}+M_{F E}^{\text {extra }}$.

\section{Results and Discussion}

\subsection{Specimens Type01-Without Skins}

In the previous section the problem related to trusses' diameter was discussed and it was demonstrated, with simple mass measurements, how the nominal diameter is to be considered reduced by $18 \%$ and therefore equal to $0.8183 \mathrm{~mm}$. Nevertheless, this value only guarantees to respect the mass requirement, nothing is guaranteed regarding the structural behavior (stiffness and strength). To this end, a three-point bending test on a $270 \times 30 \times 9 \mathrm{~mm}$ specimen was numerically simulated as a further confirmation about the error which could be produced using the nominal diameter to carry out structural performance evaluations, Figure 11 shows the results of both the model with nominal diameter $\left(\mathrm{D}_{\mathrm{T}}=1.0 \mathrm{~mm}\right)$ and the one recalculated considering the mass measurements $\left(\mathrm{D}_{\mathrm{T}}=0.8183 \mathrm{~mm}\right)$. Both numerical curves significantly overestimate the stiffness and the maximum load value. On the other hand, the maximum deformation that the beams can withstand is unchanged and therefore it does not depend by the trusses' diameter. This means that the maximum deformation remains quite constant as the diameter of the beams increase/decrease. All that, essentially, is due to the fact that these absorb the applied loads as tensile and compressive stresses. For this reason, the applied displacement at the failure load undergoes very reduced changes.

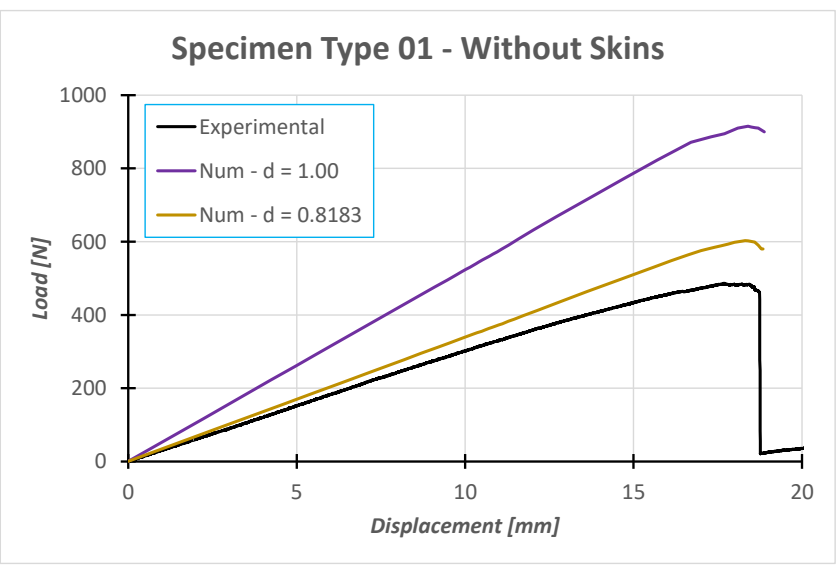

Figure 11. Experimental-numerical comparison using the nominal diameter and the one evaluated on the measured mass.

The experimental maximum load is equal to $486 \mathrm{~N}$ (based on three tests, with $\mathrm{CoV}=3.2 \%$ ) and the evaluated stiffness is about $30 \mathrm{~N} / \mathrm{mm}$. The model with the nominal diameters provides an error of $+88 \%$ and $+74.5 \%$, respectively, while the model with $\mathrm{D}_{\mathrm{T}}$ equal to $0.8183 \mathrm{~mm}$ (evaluated by the measured mass) gives an error of about $+24 \%$ and $+13 \%$, respectively.

In order to evaluate the influence of the parameter $\mathrm{D}_{\mathrm{T}}$, several simulations were performed considering several diameters. Figure 12 shows a comparison among different models; the stiffness decreases non-linearly with the diameter reduction. The best match is obtained with a diameter equal to $0.77 \mathrm{~mm}$ that provides a true mass equal to $57.32 \mathrm{~g} \mathrm{(}-10 \%$ 
w.r.t the experimental value). Table 4 reports the main results in terms of maximum load, the beam's diameter, FE mass, stiffness and displacement at maximum load (that it is different w.r.t to failure load). The failure loads were calculated by means of a simple procedure of progressive degradation of the mechanical properties of the material. The damage triggers as soon as the maximum axial stress is reached in one of the section integration points of the beam elements, at least (each beam element has 16 section integration points, two in the radial direction and eight in the circumferential direction).

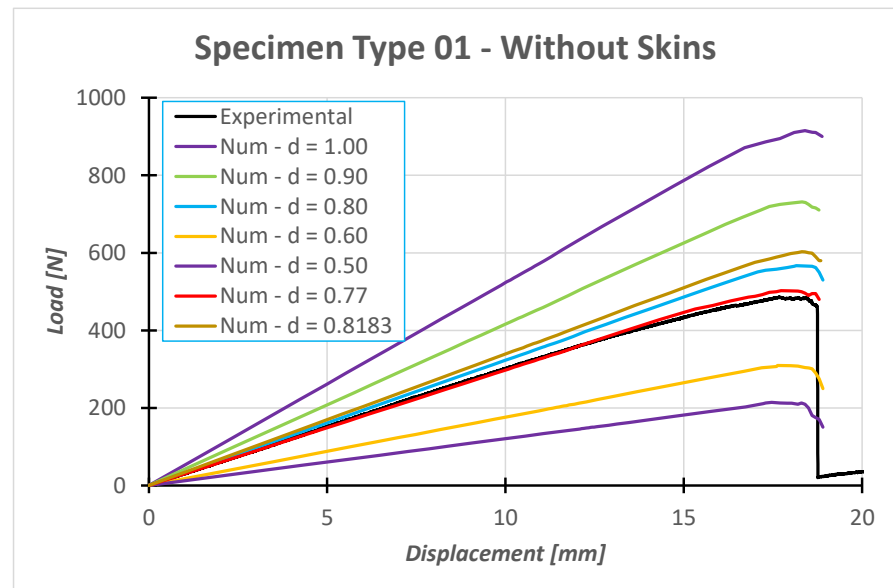

Figure 12. Influence of trusses' diameters on the structural performance of specimen Type01.

Table 4. Sensitivity analysis results -Specimen Type01.

\begin{tabular}{|c|c|c|c|c|c|c|c|c|c|}
\hline Case ID & Mass (g) & $\begin{array}{l}\text { Diameter } \\
(\mathrm{mm})\end{array}$ & $\begin{array}{l}\text { Max Load } \\
\text { (N) }\end{array}$ & $\begin{array}{l}\text { Diplacement @ } \\
\text { Max Load (mm) }\end{array}$ & $\begin{array}{l}\text { Stiffness } \\
(\mathrm{N} / \mathrm{mm})\end{array}$ & $\begin{array}{c}\text { Mass } \\
\text { Error (\%) }\end{array}$ & $\begin{array}{c}\text { Load } \\
\text { Error (\%) }\end{array}$ & $\begin{array}{c}\text { Disp } \\
\text { Error (\%) }\end{array}$ & $\begin{array}{l}\text { Stiffness } \\
\text { Error (\%) }\end{array}$ \\
\hline Experimental & 63.81 & - & 486.00 & 17.69 & 30.00 & - & - & - & - \\
\hline $\begin{array}{l}\text { Num-T01-01 } \\
\text { (Nominal) }\end{array}$ & 90.08 & 1.000 & 915.36 & 18.40 & 52.35 & 41.16 & 88.35 & 3.99 & 74.49 \\
\hline Num-T01-02 & 75.29 & 0.900 & 731.26 & 18.32 & 41.62 & 17.98 & 50.46 & 3.54 & 38.74 \\
\hline Num-T01-03 & 61.32 & 0.800 & 567.21 & 18.16 & 32.31 & -3.90 & 16.71 & 2.61 & 7.70 \\
\hline Num-T01-04 & 48.35 & 0.700 & 428.62 & 17.71 & 24.33 & -24.22 & -11.81 & 0.09 & -18.89 \\
\hline Num-T01-05 & 36.56 & 0.600 & 309.13 & 17.63 & 17.61 & -42.71 & -36.39 & -0.35 & -41.30 \\
\hline Num-T01-06 & 26.10 & 0.500 & 214.25 & 17.47 & 12.07 & -59.09 & -55.92 & -1.30 & -59.77 \\
\hline Num-T01-07 & 63.81 & 0.818 & 602.56 & 18.31 & 33.91 & 0.00 & 23.98 & 3.49 & 13.04 \\
\hline Num-T01-08 & 57.32 & 0.770 & 502.25 & 17.73 & 29.78 & -10.17 & 3.34 & 0.21 & -0.73 \\
\hline
\end{tabular}

Figure 12 highlights that the global failure occurs in a very reduced applied displacement range, but the relative loads are clearly different. All this indicates that the numerical failure occurs mainly due to tension and/or compression stress state, and such stress components depend only by the deformation state and by axial modulus. Since the deformation state is imposed by the displacement of the loading block, elements with different diameters will reach the same critical values of stress for the same level of deformation (regardless of the section). On the other hand, the reaction load is a function of the beam diameter and therefore of the global stiffness.

The best model $\left(\mathrm{D}_{\mathrm{T}}=0.77 \mathrm{~mm}\right)$ provides a very reduced error in terms of all main structural parameters: stiffness, strength, maximum load. The last ones are, respectively: $-0.73 \%,+0.21 \%$ and $+3.34 \%$. Figure 13 reports a graphical experimental-numerical comparison in terms of deformed shape for three different load steps (applied displacement): $2.15 \mathrm{~mm}, 13.8 \mathrm{~mm}$ and $17.7 \mathrm{~mm}$. The last load step corresponds to the maximum load that is $486 \mathrm{~N}$ for the experimental test and $502 \mathrm{~N}$ for the numerical simulation, and after this load step total failure occurs. 


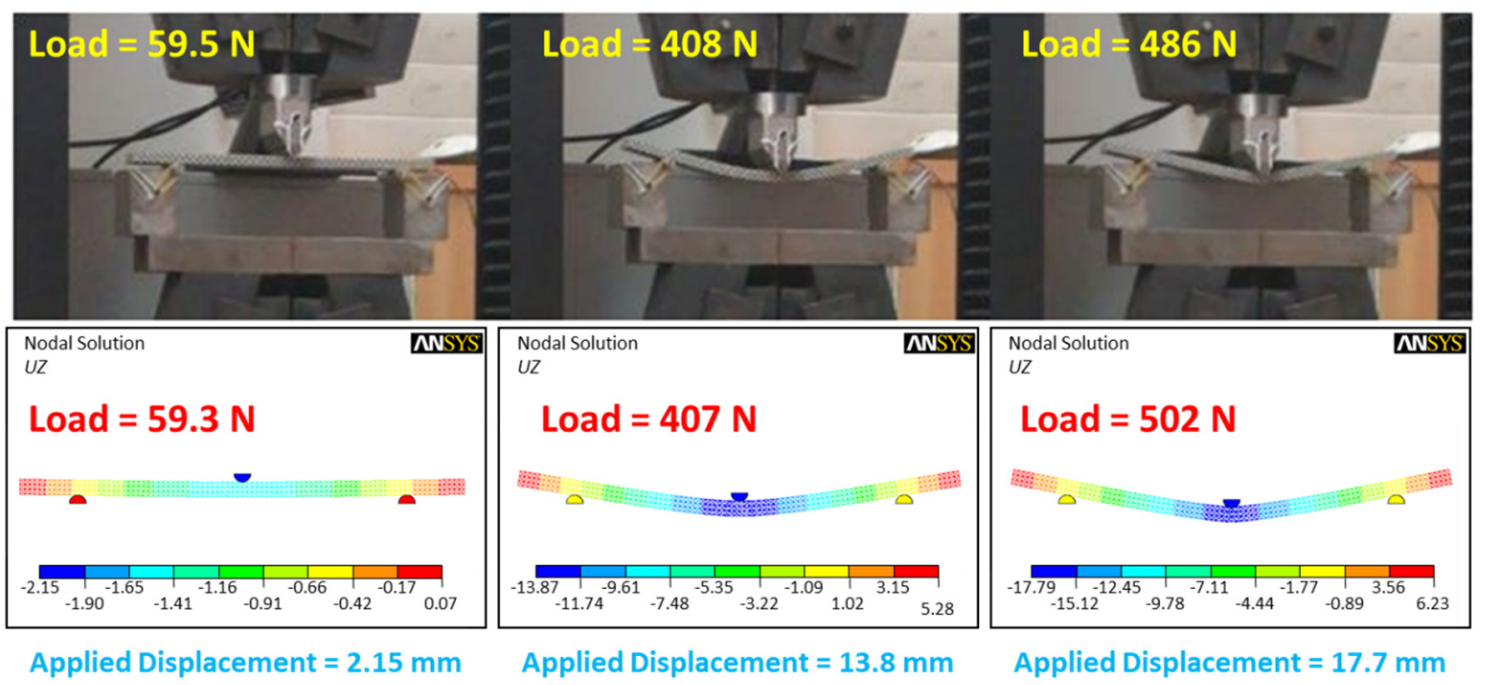

Figure 13. Experimental-numerical comparison in terms of deformed shape for specimen Type01. The numerical results reproduce the displacement along the loading direction.

Despite the good correlation achieved, it is important to note that these results were obtained by means of a further reduction of the trusses' diameter and therefore of the total mass, which is decreased up to about $57 \mathrm{~g}(-10 \%$ w.r.t the experimental data). This mass reduction could be compatible with the hypothesis that part of the measured mass is not allocated to play a structural role, in fact a small amount of partially synthetized powder could be stuck in the cavities (the structure has a very complex topology and all regions are not fully accessible). Such an amount of material contributes to the total mass of the component, but it provides a very small contribution in terms of stiffness. A further cause could consist in the non-homogeneity of the mechanical properties within the sections of the trusses, in addition, of course, the sections are not perfectly circular. In fact, as it can be seen from Figure 14, the surface of the truss is quite irregular, and its roughness is very high; therefore, the presence of these defects alters the mechanical characteristics of the material, because their effect is comparable to the notch one. In the same figure, it can be seen that the diameter of the trusses changed depending on the truss direction. All these issues highlight the extreme complexity in defining a reliable and accurate numerical model to be used for possible design activities regarding the lattice structures. In this context, the main goal of the present work is to define an efficient numerical approach from the computational point of view, therefore the proposed methodologies are easy to manage and to implement.
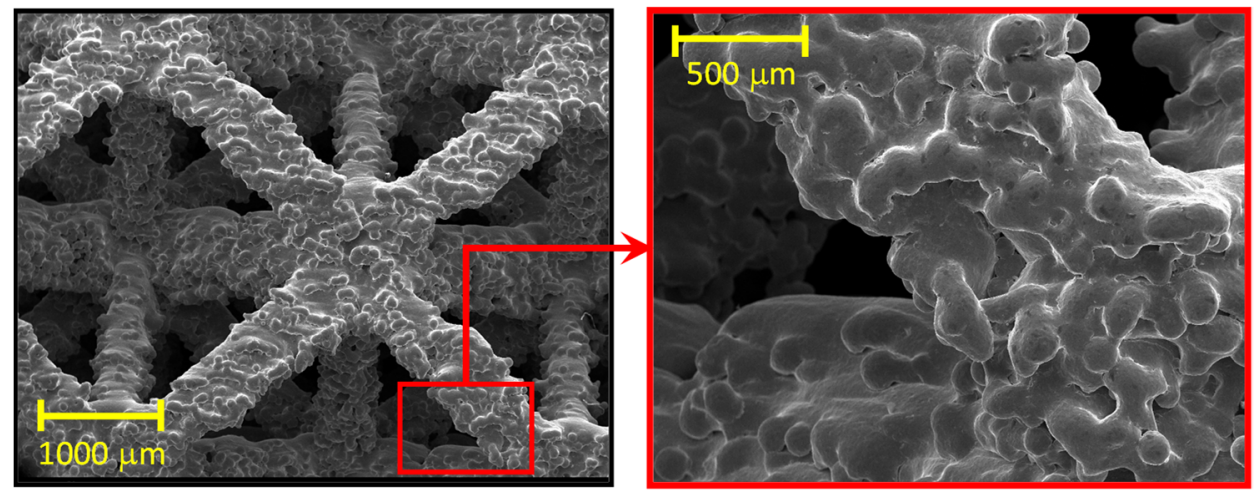

Figure 14. A micrograph of the lattice structure, denoting the surface roughness of trusses. 


\subsection{Specimens Type02-With Outer Skins}

The numerical analyses of the specimens with the outer skins highlighted similar problems to the previous case, indeed, also in this case, adopting the nominal geometrical parameters leads to a clear overestimation of the global flexural stiffness and mass. Before performing a sensitivity analysis to estimate the effective thickness of skins, some considerations about the measured mass must be taken into account.

The average measured mass (three specimens) is equal to $96.88 \mathrm{~g}$, and, since the inner lattice structure is the same as in specimen Type01, it is possible to define the mass of upper and lower skins, i.e., $M_{\text {skin }}=(96.88-63.81) / 2=16.535 \mathrm{~g}$. The nominal skin thickness is $0.6 \mathrm{~mm}$ and therefore the relative mass is equal to $21.384 \mathrm{~g}$ (single skin). After the manufacturing process the mass reduction of the skin is about $-22.6 \%$. The in-plane dimensions changes are neglectable and thus the mass reduction is due to the thickness reduction that is $-22.6 \%$. Such a mass reduction corresponds to a skin thickness equal to $0.464 \mathrm{~mm}$. In this case the FE model does not introduce any extra mass. The sections of the shell elements are offset to avoid any critical penetrations with the beam elements.

Also in this case, the evaluated mass reduction, based on the mass measurement, is not able to provide the right global stiffness and thus a further thickness reduction has to be applied. The further reduction is evaluated considering the same reduction factor defined for the trusses' diameter that is $-5.9 \%$ (i.e., $(0.77-0.8183) / 0.8183=-0.05902)$. Therefore, the adopted skins' thickness is $0.436 \mathrm{~mm}$.

The diameter of the trusses defined in the previous section was considered for models with the outer skins. The structural response was then evaluated with the integration of the skins. In order to produce a more exhaustive evaluation, in addition to the analytically determined thickness, several skins' thicknesses were evaluated, including the nominal one $(0.6,0.5$ and $0.4 \mathrm{~mm})$. Figure 15 shows the load-displacement curves both for the experimental tests and for the numerical simulations. The figure reports also the results related to model with the nominal data, which leads to a considerable error.

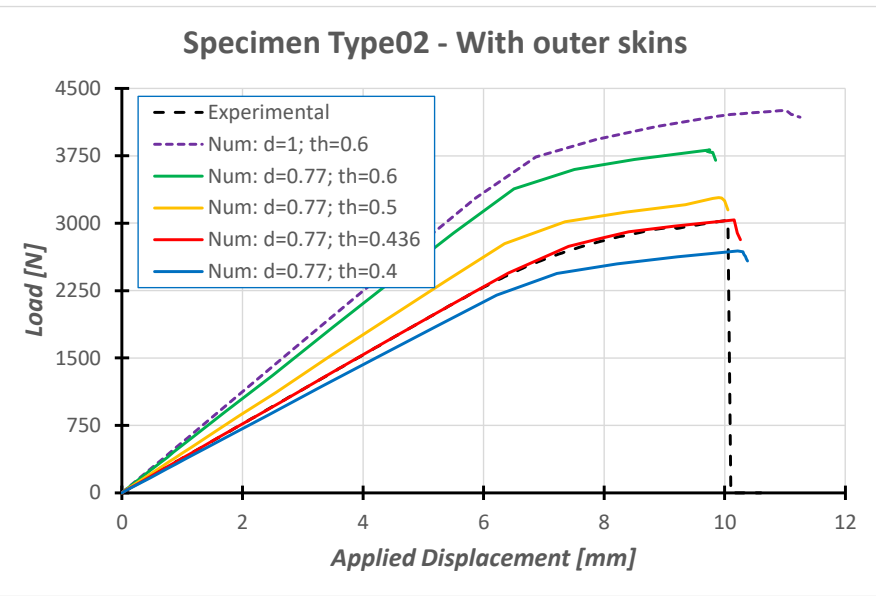

Figure 15. Reaction load vs. applied displacement for specimens Type02.

The model with the thickness equal to $0.436 \mathrm{~mm}$ is the one that provides the best correlation with the experimental data. This shows that, even if quite approximate, the developed methodology allows one to obtain excellent results. Also in this case, use of the nominal parameters leads to a clear overestimation of the mechanical response of the lattice structure, both in terms of stiffness and strength. The maximum applied displacement is slightly affected by the thickness of the skins: it increases as the thickness of the skin decreases.

Table 5 reports all results for all investigated numerical model. The model Num-T02-05 that implements the evaluated geometrical parameters provides a very reduced error for all structural outputs. In particular the error related to the global stiffness is about $0.05 \%$. 
both experimental and numerical stiffness was evaluated in the linear-elastic regime and in particular in the range $3-5 \mathrm{~mm}$.

Table 5. Sensitivity analysis results -Specimen Type02.

\begin{tabular}{|c|c|c|c|c|c|c|c|c|c|c|}
\hline Case ID & $\begin{array}{c}\text { Mass } \\
\text { (g) }\end{array}$ & $\begin{array}{l}\text { Diameter } \\
(\mathrm{mm})\end{array}$ & $\begin{array}{l}\text { Skin Th } \\
\text { (mm) }\end{array}$ & $\begin{array}{c}\text { Max } \\
\text { Load (N) }\end{array}$ & $\begin{array}{l}\text { Dip @ Max } \\
\text { Load (mm) }\end{array}$ & $\begin{array}{l}\text { Stiffness } \\
(\mathrm{N} / \mathrm{mm})\end{array}$ & $\begin{array}{c}\text { Mass } \\
\text { Error (\%) }\end{array}$ & $\begin{array}{c}\text { Load } \\
\text { Error }(\%)\end{array}$ & $\begin{array}{c}\text { Disp } \\
\text { Error (\%) }\end{array}$ & $\begin{array}{l}\text { Stiffness } \\
\text { Error (\%) }\end{array}$ \\
\hline Experimental & 96.88 & - & - & 3050.25 & 10.10 & 383.83 & - & - & - & - \\
\hline $\begin{array}{l}\text { Num-T01-01 } \\
\text { (Nominal) }\end{array}$ & 117.83 & 1.00 & 0.600 & 4254.56 & 11.01 & 561.60 & 37.12 & 39.48 & 9.09 & 46.31 \\
\hline Num-T02-02 & 100.09 & 0.77 & 0.600 & 3815.16 & 9.75 & 526.58 & 3.31 & 25.08 & -3.40 & 37.19 \\
\hline Num-T02-03 & 92.96 & 0.77 & 0.500 & 3285.00 & 9.90 & 440.24 & -4.05 & 7.70 & -1.94 & 14.69 \\
\hline Num-T02-04 & 85.83 & 0.77 & 0.400 & 2691.29 & 10.21 & 356.24 & -11.41 & -11.77 & 1.18 & -7.19 \\
\hline Num-T02-05 & 88.40 & 0.77 & 0.436 & 3038.16 & 10.16 & 384.02 & -8.76 & -0.40 & 0.62 & 0.05 \\
\hline
\end{tabular}

Figure 16A shows the specimen at the end of experimental test and thus the permanent deformed state and after failure occurred. The averaged experimental maximum load is equal to $3050.25 \mathrm{~N}$ (based on three tests; $\mathrm{CoV}=2.8 \%$ ). Figure $16 \mathrm{~B}$ shows the permanent deformation state in terms of global displacement at the maximum load value, that is $3038.2 \mathrm{~N}$ and the relative applied displacement is about $10.2 \mathrm{~mm}$. The fracture that starts near the center section generates a distension of two ends which are, therefore, almost linear. Figure 16C, on the other hand, shows the damage state at the end of the simulations, therefore in correspondence with an applied displacement of about $10.5 \mathrm{~mm}$. The failure affects both the skins and the inner lattice core. An element is considered damaged if the deformation state has exceeded the admissible values in at least one integration point. After the failure, the mechanical properties are degraded until reaching a stiffness e equal to 0 .
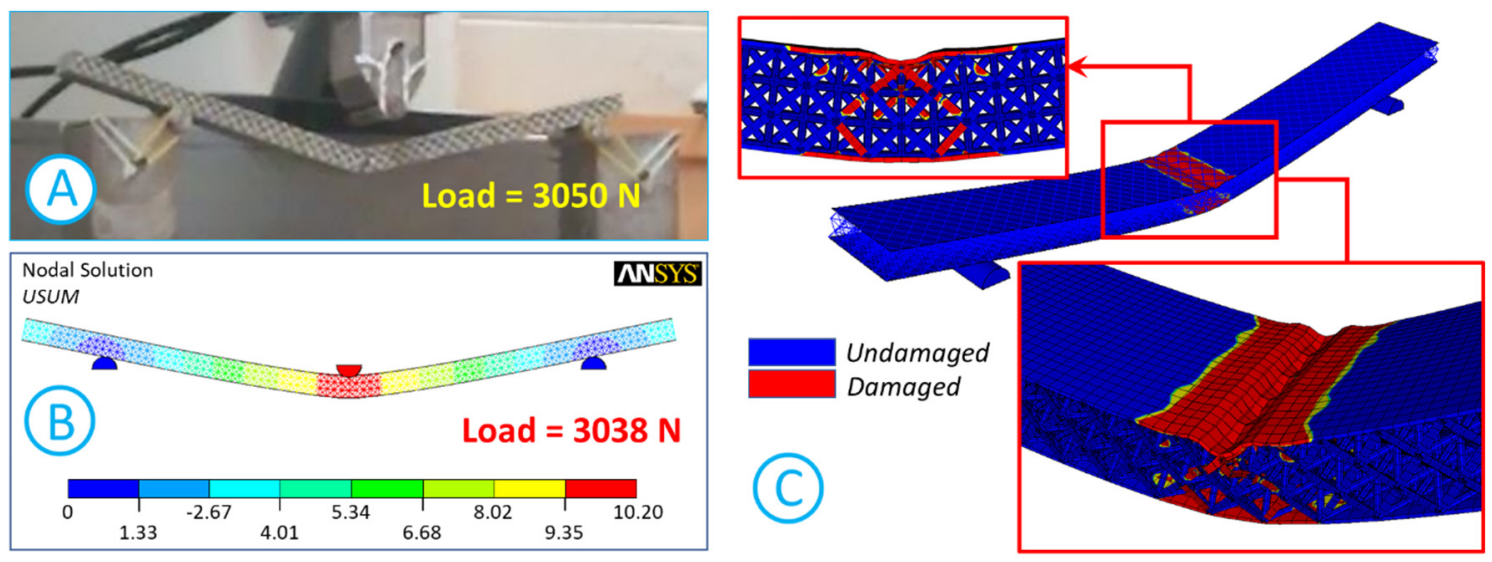

Figure 16. Numerical results of specimen Type02. (A) Experimental failure and deformed state; (B) global displacement at maximum load; (C) Damage status after maximum applied displacement.

\section{Conclusions}

The numerical approach, reported in the present work, aims to provide a methodology for the calibration of numerical models to be used for the evaluation of the mechanical performances of metallic lattice structures produced by means of additive technologies. The approach is based on simplified FE models with a reduced computational cost, so the models consist of beam and shell elements. The bending behavior of two types of two lattice structures, one with skin and another one without, was simulated to evaluate the utility of the proposed model.

A first comparison between the mass of the produced structure, without the skin, and that of the nominal one, with a truss diameter of $1 \mathrm{~mm}$, evidenced an overestimation of $18 \%$, being the former equal to $63.810 \mathrm{~g}$ and the latter $90.076 \mathrm{~g}$. Therefore, CAD software was used to determine a correlation law between the truss diameter and the mass, and a diameter of $0.8183 \mathrm{~mm}$ was determined to obtain a mass equal to that one of the produced 
structures. However, the mechanical characteristics of such structure were higher than those evaluated experimentally, being the difference between maximum experimental load and numerical one equal to $23.98 \%$. Moreover, the differences between experimental and numerical values for the maximum displacement and the stiffness were $3.49 \%$ and $13.04 \%$, respectively. Therefore, the numerical model was used to find the right value of the diameter to obtain the matching between numerical and experimental results. A diameter of $0.770 \mathrm{~mm}$ was found appropriate to obtain errors of $3.34 \%, 0.21 \%$, and $-0.73 \%$ for the maximum load, maximum displacement, and stiffness, respectively. However, the difference between the weight of the produced structures and the CAD ones was $10.17 \%$.

The abovementioned methodology was applied to the structure with skin too. In such a case, considering a truss diameter of $0.770 \mathrm{~mm}$, a skin thickness of $0.436 \mathrm{~mm}$ was found suitable to obtain an error of $-0.40 \%$ for the maximum load, $0.62 \%$ for the maximum displacement and $0.05 \%$ for the thickness. However, the mass resulted underestimated, with an error equal to $-8.76 \%$.

The excellent correlation level achieved shows that it is possible to properly calibrate numerical models without excessively increasing the complexity of the model itself. However, the analyses also highlighted a weakness of the proposed approach: the determination of the effective diameter of the trusses cannot take place only with mass data, but mechanical information is needed too. This could be justified by several factors, such as:

- The mechanical properties are not constant within the trusses' section. It is thus possible that the outer regions (a sort of skin of the trusses) have degraded properties;

- Small amount of not-fully synthesized powder and therefore not removed during post-process operations may have affected the mass measurement;

- The trusses' cross-sections are not constant along the entire truss span (geometrical tolerances). The pinching areas act as stress concentrators, and have lower stiffness;

- A widespread and non-homogenous defect status (which could include the porosity too) could lead to a localized reduction of the mechanical characteristics but does not affect the global mass measurement.

All the above options could be analyzed from a numerical point of view only by developing finer and more sophisticated FE models. However, it is important to try to accomplish two goals: (i) to reduce the computation cost for using such techniques in common/commercial applications; (ii) to preserve the 3D-modellization for the unit cells in order to evaluate the real structural contribution of each truss of each cell and, thus, how the loading paths can be redefined after the failure of some elements (multi-path load structures).

Author Contributions: Conceptualization, F.D.C., S.F., R.B., C.B. and L.S.; methodology, F.D.C., R.B., S.F. and L.S.; software, F.D.C.; validation, F.D.C., R.B., C.B. and V.D.C.; data curation, S.F., R.B. and C.B.; writing—original draft preparation, F.D.C., S.F., R.B., C.B. and L.S.; visualization, F.D.C., S.F., R.B., C.B. and L.S.; supervision, L.S. and V.D.C.; funding acquisition, L.S. All authors have read and agreed to the published version of the manuscript.

Funding: This research was supported by POR FESR Lazio 2014-2020, Strategic Projects-AoS Aerospace [AMHybridStructures project, 28143, rif. G06734/2020].

Data Availability Statement: Not applicable.

Conflicts of Interest: The authors declare no conflict of interest.

\section{References}

1. Maskery, I.; Aboulkhair, N.T.; Aremu, A.O.; Tuck, C.J.; Ashcroft, I.A.; Wildman, R.D.; Hague, R. A mechanical property evaluation of graded density Al-Si10-Mg lattice structures manufactured by selective laser melting. Mater. Sci. Eng. A 2016, 670, 264-274. [CrossRef]

2. Bellini, C.; Borrelli, R.; Di Cocco, V.; Franchitti, S.; Iacoviello, F.; Sorrentino, L. Bending properties of titanium lattice structures produced by EBM process. Fatigue Fract. Eng. Mater. Struct. 2021, 44, 1961-1970. [CrossRef]

3. Bellini, C.; Borrelli, R.; Di Cocco, V.; Franchitti, S.; Iacoviello, F.; Sorrentino, L. Damage analysis of Ti6Al4V lattice structures manufactured by electron beam melting process subjected to bending load. Mater. Des. Process. Commun. 2021, 3, e223. [CrossRef] 
4. Liu, L.; Kamm, P.H.; García-Moreno, F.; Banhart, J.; Pasini, D. Elastic and failure response of imperfect three-dimensional metallic lattices: The role of geometric defects induced by Selective Laser Melting. J. Mech. Phys. Solids 2017, 107, 160-184. [CrossRef]

5. Bellini, C.; Borrelli, R.; Di Cocco, V.; Franchitti, S.; Iacoviello, F.; Sorrentino, L. Titanium lattice structures manufactured by EBM process: Effect of skin material on bending characteristics. Eng. Fract. Mech. 2021, 260, 108180. [CrossRef]

6. Dong, G.; Tang, Y.; Zhao, Y.F. A Survey of Modeling of Lattice Structures Fabricated by Additive Manufacturing. J. Mech. Des. 2017, 139, 100906. [CrossRef]

7. Epasto, G.; Palomba, G.; D'Andrea, D.; Guglielmino, E.; Di Bella, S.; Traina, F. Ti-6Al-4V ELI microlattice structures manufactured by electron beam melting: Effect of unit cell dimensions and morphology on mechanical behaviour. Mater. Sci. Eng. A 2019, 753, 31-41. [CrossRef]

8. Mahbod, M.; Asgari, M. Elastic and plastic characterization of a new developed additively manufactured functionally graded porous lattice structure: Analytical and numerical models. Int. J. Mech. Sci. 2019, 155, 248-266. [CrossRef]

9. Bellini, C.; Borrelli, R.; Di Cocco, V.; Franchitti, S.; Iacoviello, F.; Mocanu, L.P.; Sorrentino, L. Failure energy and stiffness of titanium lattice specimens produced by electron beam melting process. Mater. Des. Process. Commun. 2021, 3, e268. [CrossRef]

10. Bellini, C.; Borrelli, R.; Di Cocco, V.; Franchitti, S.; Iacoviello, F.; Sorrentino, L. Potentiality of hybrid structures in CFRP and additive manufactured metal octet-truss lattice. Procedia Struct. Integr. 2020, 28, 667-674. [CrossRef]

11. Ashby, M. Hybrid Materials to Expand the Boundaries of Material-Property Space. J. Am. Ceram. Soc. 2011, 94, s3-s14. [CrossRef]

12. Ashby, M. Designing architectured materials. Scr. Mater. 2013, 68, 4-7. [CrossRef]

13. Fleck, N.A.; Deshpande, V.S.; Ashby, M.F. Micro-architectured materials: Past, present and future. Proc. R. Soc. A Math. Phys. Eng. Sci. 2010, 466, 2495-2516. [CrossRef]

14. Deshpande, V.S.; Ashby, M.F.; Fleck, N.A. Foam topology: Bending versus stretching dominated architectures. Acta Mater. 2001, 49, 1035-1040. [CrossRef]

15. Deshpande, V.S.; Fleck, N.A.; Ashby, M.F. Effective properties of the octet-truss lattice material. J. Mech. Phys. Solids 2001, 49, 1747-1769. [CrossRef]

16. Del Guercio, G.; Galati, M.; Saboori, A.; Fino, P.; Iuliano, L. Microstructure and Mechanical Performance of Ti-6Al-4V Lattice Structures Manufactured via Electron Beam Melting (EBM): A Review. Acta Met. Sin. (Engl. Lett.) 2020, 33, 183-203. [CrossRef]

17. Echeta, I.; Feng, X.; Dutton, B.; Leach, R.; Piano, S. Review of defects in lattice structures manufactured by powder bed fusion. Int J. Adv. Manuf. Technol. 2020, 106, 2649-2668. [CrossRef]

18. Bellini, C.; Berto, F.; Di Cocco, V.; Iacoviello, F.; Mocanu, L.P.; Razavi, J. Additive manufacturing processes for metals and effects of defects on mechanical strength: A review. Procedia Struct. Integr. 2021, 33, 498-508. [CrossRef]

19. DebRoy, T.; Wei, H.L.; Zuback, J.S.; Mukherjee, T.; Elmer, J.W.; Milewski, J.O.; Beese, A.M.; Wilson-Heid, A.; De, A.; Zhang, W Additive manufacturing of metallic components-Process, structure and properties. Prog. Mater. Sci. 2018, 92, 112-224. [CrossRef]

20. Razavi, S.; Bordonaro, G.; Ferro, P.; Torgersen, J.; Berto, F. Porosity effect on tensile behavior of Ti-6Al-4V specimens produced by laser engineered net shaping technology. Proc. Inst. Mech. Eng. Part C J. Mech. Eng. Sci. 2021, 235, 1930-1937. [CrossRef]

21. Smith, T.R.; Sugar, J.D.; Schoenung, J.; Marchi, C.S. Relationship between manufacturing defects and fatigue properties of additive manufactured austenitic stainless steel. Mater. Sci. Eng. A 2019, 765, 138268. [CrossRef]

22. Barriobero-Vila, P.; Vallejos, J.M.; Gussone, J.; Haubrich, J.; Kelm, K.; Stark, A.; Schell, N.; Requena, G. Interface-Mediated Twinning-Induced Plasticity in a Fine Hexagonal Microstructure Generated by Additive Manufacturing. Adv. Mater. 2021, 33, 2105096. [CrossRef]

23. Hernández-Nava, E.; Smith, C.J.; Derguti, F.; Tammas-Williams, S.; Léonard, F.; Withers, P.J. The effect of defects on the mechanical response of Ti-6Al-4V cubic lattice structures fabricated by electron beam melting. Acta Mater. 2016, 108, 279-292. [CrossRef]

24. Ferrigno, A.; Di Caprio, F.; Borrelli, R.; Auricchio, F.; Vigliotti, A. The mechanical strength of Ti-6Al-4V columns with regular octet microstructure manufactured by electron beam melting. Materialia 2019, 5, 100232. [CrossRef]

25. Cheah, C.-M.; Chua, C.-K.; Leong, K.-F.; Cheong, C.-H.; Naing, M.-W. Automatic Algorithm for Generating Complex Polyhedral Scaffold Structures for Tissue Engineering. Tissue Eng. 2004, 10, 595-610. [CrossRef] [PubMed]

26. Cheah, C.; Chua, C.; Leong, K.; Chua, S. Development of a Tissue Engineering Scaffold Structure Library for Rapid Prototyping. Part 1: Investigation and Classification. Int. J. Adv. Manuf. Technol. 2003, 21, 291-301. [CrossRef]

27. Wang, X.; Xu, S.; Zhou, S.; Xu, W.; Leary, M.; Choong, P.; Qian, M.; Brandt, M.; Xie, Y.M. Topological design and additive manufacturing of porous metals for bone scaffolds and orthopaedic implants: A review. Biomaterials 2016, 83, 127-141. [CrossRef] [PubMed]

28. Rodrigues, H.; Guedes, J.; Bendsoe, M. Hierarchical optimization of material and structure. Struct. Multidiscip. Optim. 2002, 24, 1-10. [CrossRef]

29. Huang, X.; Radman, A.; Xie, Y.M. Topological design of microstructures of cellular materials for maximum bulk or shear modulus. Comput. Mater. Sci. 2011, 50, 1861-1870. [CrossRef]

30. Wang, C.; Zhu, J.H.; Zhang, W.H.; Li, S.Y.; Kong, J. Concurrent topology optimization design of structures and non-uniform parameterized lattice microstructures. Struct. Multidiscip. Optim. 2018, 58, 35-50. [CrossRef]

31. Chen, W.; Tong, L.; Liu, S. Concurrent topology design of structure and material using a two-scale topology optimization. Comput. Struct. 2017, 178, 119-128. [CrossRef]

32. Hassani, B.; Hinton, E. A review of homogenization and topology I-Homogenization theory for media with periodic structure. Comput. Struct. 1998, 69, 707-717. [CrossRef] 
33. Hassani, B.; Hinton, E. A review of homogenization and topology optimization II-analytical and numerical solution of homogenization equations. Comput. Struct. 1998, 69, 719-738. [CrossRef]

34. Chen, W.; Zheng, X.; Liu, S. Finite-Element-Mesh Based Method for Modeling and Optimization of Lattice Structures for Additive Manufacturing. Materials 2018, 11, 2073. [CrossRef]

35. Rosen, D.W. Computer-Aided Design for Additive Manufacturing of Cellular Structures. Comput. Des. Appl. 2007, 4, 585-594. [CrossRef]

36. Zhang, Y.; Bernard, A.; Gupta, R.K.; Harik, R. Evaluating the Design for Additive Manufacturing: A Process Planning Perspective. Procedia CIRP 2014, 21, 144-150. [CrossRef]

37. Di Caprio, F.; Acanfora, V.; Franchitti, S.; Sellitto, A.; Riccio, A. Hybrid Metal/Composite Lattice Structures: Design for Additive Manufacturing. Aerospace 2019, 6, 71. [CrossRef]

38. Franchitti, S.; Pirozzi, C.; Borrelli, R. Influence of hot isostatic pressing and surface finish on the mechanical behaviour of Ti6Al4V processed by electron beam melting. Fatigue Fract. Eng. Mater. Struct. 2020, 43, 2828-2841. [CrossRef]

39. Körner, C. Additive manufacturing of metallic components by selective electron beam melting-A review. Int. Mater. Rev. 2016, 61,361-377. [CrossRef]

40. ARCAM, Arcam A2X-For Aerospace Production and Materials R\&D. 2018. Available online: http://www.arcam.com/wpcontent/uploads/arcam-a2x.pdf (accessed on 1 January 2022).

41. Neira-Arca, A. Thermal Modeling and Simulation of Electron Beam Melting for Rapid Prototyping on Ti6Al4V Alloys. Ph.D. Thesis, North Carolina State University, Raaleigh, NC, USA, 2012. 